\title{
Silicon mobilization in soils: the broader impact of land use
}

\author{
Lúcia Barão ${ }^{1,2^{*}}$, Ricardo Teixeira ${ }^{3}$, Floor Vandevenne ${ }^{4}$, Benedicta Ronchi ${ }^{5,6}$, Dácil Unzué- \\ Belmonte ${ }^{4}$, Eric Struyf ${ }^{4}$ \\ 1 Center for Ecology, Evolution, and Environmental Changes (cE3c), University of Lisbon. Faculdade de Ciências da Universidade de Lisboa, \\ 1749-016 Lisboa, Portugal. \\ 2 Institute of Mediterranean Agricultural and Environmental Sciences (ICAAM), University of Évora, Depto de Fitotecnia. P-7002-554 Évora, \\ Portugal \\ 3 MARETEC-Marine, Environment and Technology Centre, LARSyS, Instituto Superior Técnico, Universidade de Lisboa, Pavilhão de Mecânica \\ I, Av. Rovisco Pais, 1, 1049-001 Lisbon \\ 4 Department of Biology, Ecosystem Management Research Group, University of Antwerp, Universiteitsplein 1C 2610, Wilrijk, Belgium \\ 5 Katholieke Universiteit Leuven, Department of Earth and Environmental Sciences, Celestijnenlaan 200E, 3001 Leuven, Belgium \\ 6 Institut Scientifique du Service Public, Rue du Chéra 200, 4000 Liège Belgium \\ *Contacting Author: albarao@fc.ul.pt \\ Barão, L., Teixeira, R., Vandevenne, F. et al. Silicon Mobilization in Soils: the Broader Impact of \\ Land Use. Silicon 12, 1529-1538 (2020). https://doi.org/10.1007/s12633-019-00245-y

\section{ABSTRACT}

Dissolved $\mathrm{Si}$ (DSi) provision from land systems triggers diatom growth and $\mathrm{CO}_{2}$ sequestration. Soils and ecosystems act as a Si "filter", transforming DSi originated from mineral weathering into biogenic Si (BSi) after DSi uptake by plants, or into other pedogenic forms of Si (non-BSi). Land use changes the quantity of BSi and non-BSi pools along the soil profile. However, methods used to isolate Si pools include chemical extractions at high temperatures and alkaline environments and therefore are unable to provide information concerning the dissolution potential of BSi and non-BSi pools under normal conditions of temperature and $\mathrm{pH}$.

Here, we conducted a batch experiment where forest, pasture and cropland soil samples were mixed with water at $25{ }^{\circ} \mathrm{C}$ and $\mathrm{pH} 7$. The soil samples were collected from a temperate land use gradient located in the Belgian Loess Belt. We measured dissolved Si and aluminium (Al) during 80 days. BSi and non-BSi pool contents along the soil profile were known, as they had been established previously through chemical extraction.

Results show that BSi and non-BSi enriched samples present distinct $\mathrm{Si}$ and Al dissolution curves. While non-BSi pools contribute significantly with immediate availability of $\mathrm{Si}$, BSi pools present an initial slow dissolution.

Therefore, croplands that were depleted of phytoliths and had poorly organic horizons display higher concentrations of initial dissolved $\mathrm{Si}$, while pastures and forests, where pedogenic pools dominate only at depths below $40 \mathrm{~cm}$, have more limited initial Si release.

KEYWORDS: Land use gradient, Availability, Batch experiment, Silicon pools 
Unravelling the silicon (Si) cycle in terrestrial and aquatic Earth surface systems is of strong interest due to its interaction with climate regulation [1]. Silicate minerals are largely abundant in the Earth crust. They are subject to weathering under the proper physical/chemical conditions and provide soluble mineral elements - including dissolved $\mathrm{Si}(\mathrm{DSi})$ - to the soil. During the process of weathering, $\mathrm{CO}_{2}$ is sequestered from the atmosphere $[2,3]$. This constant and slow process is also influenced by the climate itself, since weathering rates are intrinsically dependent on rain abundance and temperature [3]. The weathered DSi can eventually reach coastal areas and the ocean, where it is an essential element for the growth of diatoms [4]. This aquatic sub-cycle - and the consequent $\mathrm{CO}_{2}$ sequestration - is dependent on the mobilization of DSi from land, to replenish the biogenic $\mathrm{Si}$ (BSi) buried [5, 6]. During the last two decades, research showed that terrestrial ecosystems act as a filter for the DSi released from the Earth crust [7-9]. DSi is taken up by plants and deposited in the cell walls and other plant organs as BSi, mostly in Si-rich bodies called phytoliths $[10,11]$. The deposition density depends on the plant types, with grasses generally being the highest Si accumulators [12]. Quantification of this terrestrial bio-Si filter is of the essence for understanding the terrestrial-coastal Si linkages, and the ensuing impact on the carbon cycle.

As Si accumulated in plants returns to the soil, soils can become enriched with BSi. Phytoliths returning to the soil are one order of magnitude more soluble than silicate minerals, and biogeochemically more available $[13,14]$. They thus strongly determine the dynamics of the terrestrial soil Si cycle, along with other secondary Si forms produced by pedogenic processes [15, 16]: opal A precipitated in situ, Si adsorbed in Fe/Al hydroxides and short order range minerals $[17,18]$. Recently a jointed effort has been made by scientists to understand and describe the different reactive fractions of $\mathrm{Si}$ in soil - both biogenic and non-biogenic $[19,20]$ - as well as their variability $[21,22]$. This research is crucial to understanding the role and development of the « soil Si filter » in the global Si cycle and to foresee the consequences of terrestrial systems alterations, including land use changes.

Land use and land use change are some of the major drivers of change for the state of ecosystems. They are also significant drivers in the Si cycle [23]. In Croplands, part of the Si accumulated in plants is exported during harvesting, potentially depleting BSi stocks in the soil [24]. Also, land use change impacts the occurrence and distribution in the soil profile of pedogenic Si pools in temperate [25] and sub-tropical [26] systems. However, while the impact of land use is well established in the distribution of different Si pools along the soil profile, little 
is known about the actual contribution of different biogenic and pedogenic pools for the availability of Si in pore water [27].

This paper aims to contribute to the understanding of how different reactive Si pools impact the mobilization of DSi from soils in multiple land use types. We conducted a batch experiment in soils samples previously collected from a land use gradient [28] where the Alkaline-extractable Si pools (AlkExSi) had been separated into 4 classes:

1) BSi pool referring to the biogenic Si fractions; 2) non-BSi $i_{1}$ pool accounting for Si fractions from pedogenically formed opal CT; 3) non-BSi 2 pool referring to Si fractions from clay minerals; 4) non-BSi 3 pool accounting for $\mathrm{Si}$ fractions resulting from pedogenic processes with high levels of Al possibly associated with e.g. precursors of imogolite.

\section{MATERIAL AND METHODS}

\subsection{Soil Samples}

Soil samples along vertical profiles of $\sim 1.5 \mathrm{~m}$ were collected from two Forests (Meerdaal - Forest 1 and Ronquières - Forest 2), two Pastures (Blegny - Pasture 1 and Herve - Pasture 2) and two Croplands (Ganspoel - Cropland 1 and Velm - Cropland 2) in the region of the Belgian Loess Belt (Table 1). The three types represent different levels of land disturbance by human activity, with croplands representing the most disturbed. These sites have similar pedoclimatic conditions [27]. In a previous work [28], the samples were divided according to the depth of the soil horizon and were analysed for texture (clay, silt and sand percentage), soil water content, cation exchange capacity (CEC), $\mathrm{pH}$ and organic carbon content. Also, soil samples had been previously subjected to an alkaline continuous extraction [20] to separate the AlkExSi pools in biogenic and pedogenic fractions (Table 1). BSi and non-BSi pools thus include only fractions that are highly reactivity in alkaline environments.

\subsection{Batch experiment}

A batch experiment was conducted to evaluate Si dissolution in soil samples along the profile and from different land use types described in Table 1 . Concretely, $0.5 \mathrm{~g}$ of freeze-dried soil, previously sieved at $2 \mathrm{~mm}$, was incubated 
in $0.5 \mathrm{~L}$ of deionized water $(\mathrm{pH}=7)$ in polyethylene plastic bottles at 25 으 for 80 days. The water bottle volume was selected to be sufficiently larger than the volume of soil added to the bottle. This procedure ensured that the removal of water samples from the bottle for posterior analysis did not significantly affect the abundance of water relative to soil. The sample was initially mixed with the water and allowed to settle. At regular time intervals (smaller intervals in the beginning for more detail) $2 \mathrm{~mL}$ was sub-sampled from the surface of the bottle. Si and Al concentrations were obtained by inductively coupled plasma-optical emission spectroscopy (ICP-OES) analysis. Bottles were treated carefully to avoid any mixing. Dissolution curves were thus gathered for different combinations of sampling depth and land use. All bottles were protected with aluminium paper to avoid light interference and algae growth and were carefully closed to avoid evaporation. Three blanks were also incubated to determine potential small losses due to evaporation, but these were shown to be insignificant.

Additionally, two other similar treatments were conducted on soil sample aliquots, but where the water added to the bottle was: a) mixed with $\mathrm{HCl}$ to achieve an initial $\mathrm{pH}$ of 4 and; b) mixed with $\mathrm{NaOH}$ to achieve an initial $\mathrm{pH}$ of 10. Although not representative of natural soil $\mathrm{pH}$ values, these treatments were conducted in order to assess the initial Si release (section 2.3.) and to compare it with the readily available Si pool calculated previously for the same samples in [28] using an extraction with $0.01 \mathrm{M} \mathrm{CaCl}_{2}$.

\subsection{Si and Al dissolution model}

Data for Si dissolution curves in the batch experiment were fitted to a three-parameter non-linear model (visually depicted in Figure 2) that calculates dissolved Si as a function of time, namely

$$
\operatorname{Si}(t)=S i_{i n i}+S i_{d i s}\left(1-e^{-k_{S i} t}\right),
$$

where $S_{i n i}$ is the concentration of Si at close to zero time, i.e. it accounts for the highly soluble Si present in solution immediately after the mixing of the soil sample with the corresponding $\mathrm{pH}$ treatment in the bottle; $S i_{\text {dis }}$ is the concentration of Si reached by the end of the experiment; and $k_{s i}$ represents the reactivity of the mixture of pools, and influences the "shape of the curve", i.e. how fast or how slow it reaches a plateau. This model is commonly used for batch experiments where there is an initial fast dissolution rate followed by a period of decreasing dissolution rate [29]. 

one Al curve were fitted to the results of each batch experiment, in a total of 202 models, one per sample.

The fitting of the model was performed using SPSS 19. Before the fitting exercise, we removed outlier observations from the analysis if they were outside the $95 \%$ confidence interval for the average. In total, out of 2057 measurements for Si (corresponding to 101 samples between 19 and 22 extractions at different times for each sample - Table 1) and 2053 measurements for Al, 58 Si observations (3\%) and 42 Al observations (2\%) were removed. Deviations of the general trend can be explained by analysis errors and/or sudden movements in the bottles that lead to unexpected mixture of the sample with the treatment.

\section{RESULTS}

\subsection{Si and Al dissolution curves}

Both forest samples display the same Si and Al patterns of dissolution as a function of soil depth, despite the fact that in Meerdaal the initial and final concentrations were lower than in Ronquières. Si dissolution curves for the samples at 2 and $6 \mathrm{~cm}$ display a linear increasing trend $\left(0.06\right.$ and $0.34 \mu \mathrm{mol} \mathrm{L}^{-1}$ day $^{-1}$ for Meerdaal and Ronquiéres respectively), while the Al dissolution curve remained practically constant at low concentrations during the same period. At 22, 42 and $82 \mathrm{~cm}$ in Meerdaal and 24, 49 and $67 \mathrm{~cm}$ in Ronquières, Si dissolution curves display initial high concentrations followed by a decrease and stabilization at lower values. Finally, in both forests at 147 and $145 \mathrm{~cm}$, respectively, Si dissolution curves show a slight linear increase $\left(0.01\right.$ and $\left.0.17 \mu \mathrm{mol} \mathrm{L}^{-1} \mathrm{day}^{-1}\right)$, while Al has a distinct "S-shape" pattern and the dissolution rate reaches $18 \mu \mathrm{mol} \mathrm{Al} \mathrm{L}^{-1}$ day $^{-1}$ (Figure 2).

The two pasture soil samples also present contrasting Si and Al dissolution curves, which are variable along the soil profile, but with less variation compared to the forests. Upper samples up to $72 \mathrm{~cm}$ at Blègny and $22 \mathrm{~cm}$ in Herve show approximately linear increases of Si concentration, while Al remains approximately constant at low concentrations. Finally, the deeper samples collected at $144 \mathrm{~cm}$ in Blègny and 53 and $182 \mathrm{~cm}$ in Herve display 
The Si and Al dissolution patterns along the soil profile for the two croplands are similar. In general, samples show an approximately linear increase over time with low upward trends in Si $\left(<0.14 \mu \mathrm{mol} \mathrm{L}^{-1}\right.$ day $\left.^{-1}\right)$, while $\mathrm{Al}$ concentrations stabilized at concentrations lower than $4 \mu \mathrm{mol} \mathrm{\textrm {L } ^ { - 1 }}$ after a small initial increase in concentration (Figure 4)

\subsection{Model Parameters}

Results for the model parameterization show clear differences for different levels of soil disturbance by human intervention (Figure 5). In fact, the Si ini parameter, which accounts for the immediate Si dissolution when the soil is in contact with water, was generally higher for croplands $\left(0.15 \mathrm{mg} \mathrm{g}^{-1}<\mathrm{Si}_{\text {ini }}<0.25 \mathrm{mg} \mathrm{g}^{-1}\right)$ compared to forests and pastures, especially in the upper layers. Also, while in the croplands there was almost no difference along the soil profile, in forests and pastures Siini was lower in the upper layers (Siini $<0.11 \mathrm{mg} \mathrm{g}^{-1}$ ) and generally increased with depth $\left(0.11 \mathrm{mg} \mathrm{g}^{-1}<\mathrm{Si}_{\text {ini }}<0.29 \mathrm{mg} \mathrm{g}^{-1}\right)$. This difference was also patent in the reactivity parameter (k). Croplands registered the highest values $\left(0.03 \mathrm{~min}^{-1}<\mathrm{ksi}_{\mathrm{i}}<0.04 \mathrm{~min}^{-1}\right)$ when compared to the more pristine land use classes, where values were lower especially in the top organic layers $\left(k_{\mathrm{si}}<0.03 \mathrm{~min}^{-1}\right)$. Finally, Sidis shows the opposite trend for both pastures and forests with higher values in the topsoil, reaching $0.56 \mathrm{mg} \mathrm{g}^{-1}$, and a quick decrease in the first $40 \mathrm{~cm}$ followed by stabilization over the remaining profile. Croplands show lower $\mathrm{Si}_{\text {dis }}$ in the topsoil and concentrations remain relatively constant along the soil profile $\left(0.25 \mathrm{mg} \mathrm{g}^{-1}<\mathrm{Si}_{\text {dis }}<0.39 \mathrm{mg} \mathrm{g}^{-1}\right)$, with one exception at $20 \mathrm{~cm}$.

\subsection{Comparison with SicaCl2}

The comparison of the $\mathrm{Si}_{\mathrm{ini}}$ calculated for treatments with initial pH bottle at 4,7 and 10 with the $\mathrm{Si}_{\mathrm{CaCl}}$ pool shows significant correlations (Figure 6). The best fit occurred for $\mathrm{pH} 10(\rho=0.802)$, followed by $\mathrm{pH} 7(\rho=0.718)$ and $\mathrm{pH} 4$ $(\rho=0.700)$. The range of $\mathrm{Si}$ concentrations is however distinct when using the $\mathrm{CaCl}_{2}$ extractant method $(0-0.08 \mathrm{mg}$ $\left.\mathrm{g}^{-1}\right)$ and the Si pool calculated in the batch experiments $\left(0-0.8 \mathrm{mg} \mathrm{g}^{-1}\right)$ where water at initial different $\mathrm{pH}$ is used. 


\subsection{Si dissolution along the soil profile}

165

166

167

Results show that $\mathrm{Si}$ and $\mathrm{Al}$ dissolution curves differ along the soil profile. The origin of alkaline extractable Si (AlkExSi) pools was also variable in depth, for samples collected in forests and pastures. $\mathrm{O}$ and $\mathrm{A}$ horizons in forest and pasture sites are mainly comprised of $\mathrm{BSi}$, while the dissolution of non-BSi phases was negligible, as previously observed [28]. The abundance of BSi in the samples results in a linear Si dissolution in the batch experiment with very low initial Si concentrations, as shown by the low Sini parameters calculated for the top organic layers of these sites (Figure 2 and 3). In parallel, the Al concentrations measured along the batch experiment for these organic soil samples is much lower than the Si concentration and remain constant after an initial quick dissolution, which is consistent with the fact that these samples are mainly comprised of biogenic material such as phytoliths. The Si dissolution is therefore independent of the Al dissolution, as the latter is likely due to Al-complexed with organic matter, which is quickly released under these conditions. In the mineral horizons $(A B, B$ and $C)$ from pastures and forests and in the whole profile of the cropland sites, the patterns show higher initial Si concentrations and there is a link between the Si and Al dissolution dynamics, with some exceptions for the deepest layers. This coincides with the higher importance of non- $\mathrm{BSi}_{2}$ and non- $\mathrm{BSi}_{3}$ pools present (and consequently the absence of biogenic $\mathrm{Si}$ pools). Both reactive clays and $\mathrm{Si}$ adsorbed in Al complexes have higher contents of Al when compared to phytoliths, and therefore the Si and Al dissolution curves are similar as they come from the same source. Finally, the dissolution curves for the deeper layers of the pasture sites show unusually high concentrations of Si and are therefore linked to the presence of opal CT in high quantities (non-BSi ${ }_{1}$ ), which is probably local-specific [28].

\subsection{Significance of non-BSi pools}

The fact that we observed distinct Si and Al dissolution curves in samples where AlkaExSi pools differentiation was previously established, suggests therefore that biogenic and non-biogenic Si pools will contribute differently to the Si short-term availability in natural conditions. Phytoliths' dissolution does not contribute much to the initial Si release to solution, but eventually allows reaching higher concentrations. Non-biogenic pools, on the contrary, display high concentrations of initial Si (Sini) although through the experiment this concentration normally tended to decrease, resulting in lower concentrations of $\mathrm{Si}_{\text {dis }}$ when compared to the biogenic enriched samples. The fact 
that non-biogenic Si pools might be significant in the very short-term has been suggested before, due to the results of alkaline chemical extractions. $\mathrm{NaOH}$ chemical continuous extraction in parallel with $\mathrm{Al}$ showed that clay minerals and other pedogenic Si fractions display initial fast dissolution dynamics, very similar to amorphous silica. This was shown in aquatic samples [30] and in soil samples of different origins [25, 28, 31]. Other studies using different methods have also hinted that non-biogenic fractions occurring in the soil show similar dynamics to the biogenic Si fractions in alkaline environments [19, 21, 32]. The results of this study corroborate that the pedogenic fractions are not only reactive in alkaline and hot environments $(\mathrm{pH}>11$ and $80 \circ \mathrm{C})$, but also important in the short-term at normal temperature and $\mathrm{pH}$ conditions. They are initially even more available than the biogenic Si pool itself.

We acknowledge, however, that our results refer only to batch conditions, which is still a controlled situation and may not fully reflect the field-level effects of each land use, as water-solid interactions are more limited in real conditions. In the batch experiment, we used a large volume of water (as explained in the Materials and Methods section), but the amount of water in contact with soil in situ is certainly lower, which will condition the dissolution/precipitation dynamics. Indeed, a recent study using some of the same soil samples, but testing the DSi leaching along a column experiment, resulted in very low DSi concentrations in cropland soils [33]. This was probably the effect of the short contact time between water and soil particles as well as the limited contact surface when water is leaching due to gravity, when compared to this batch experiment. In addition, our experiment uses water with no previous Si concentration in solution. This is not likely to be the case for in situ cases, especially for deeper layers, where the leached water is probably already enriched with Si and the dissolution of both biogenic and non-biogenic pools is likely to be limited. However, we can use these batch results to understand the potential dissolution value of the different Si pools. Additional in situ experiments are needed to fully confirm results presented here.

\subsection{Using Sicac12 as a proxy for non-BSi pools}

Comparison between the Sicacl2 results from [28] and the Sini calculated in this study through the model described previously for the Si dissolution curve shows high correlation, especially at $\mathrm{pH} 10$, which suggests that both methods are capable of estimating the readily available Si pool. However, the $\mathrm{CaCl}_{2}$ extraction method has been unable to explain the origin of the highly soluble Si. Moreover, previous studies [32][34] showed that readily 
217 available Si measured with the $\mathrm{CaCl}_{2}$ extractant (or using other soft extractants) was variable along the soil profile and the higher concentrations were achieved only at depths were phytoliths were absent and therefore the source for these concentrations should be non-biogenic. In light of the present study we can establish that non-biogenic AlkExSi pools present in the soil samples resulted in higher Siini values and therefore the high correlation with Sicacl2 suggests that the non-BSi pools are the main reason for the measurement of the readily available Si pool. The large differences in the results when using the $\mathrm{CaCl}_{2}$ extractant and the batch experiment is difficult to explain, due to the similarity of the extractants. However, a possible reason for the discrepancy is the different soil/extractant ratio of the experiments, which is 100 times lower in the present study, pulling the chemical equilibrium toward the dissolved end.

\subsection{The effects of land use change in Si mobilization}

The Si cycle is disrupted by land use changes, as was firstly suggested by Struyf et al. (2010). This impact was initially focused on the decrease of biogenic Si pools in croplands due to the export from harvesting activities [24]. Later on, it was also established that land use change would have a deeper impact on the distribution and type of Si pools in the soils, rather than just its total quantity $[25,34]$. Results from this study show that land use changes greatly affect Si availability in natural conditions and croplands are the sites where the initial, short-term, Si release to solution is the highest. As so, the alteration of the soil occupation from forests/pastures to intensive agricultural lands induces a change in the abundance of biogenic and non-biogenic Si along the soil profile, which in turn controls the amount of Si readily available for plants/crops or to be exported to the riverine system. Intensive agriculture might be responsible for a homogenization of soil properties along time between the horizons, which can be observed by the organic matter, CEC and texture parameters (Table 1). As so, non-biogenic Si pools become available throughout the entire profile at relatively constant concentrations, while in the more preserved soils of forests and pastures these pedogenic pools are restrained to the lower layers. The alteration of chemical and physical conditions from one land use type to another also influences the abundance of biogenic and non-biogenic Si pools and their dissolution dynamics. Dissolution and precipitation are dependent on other soil-related processes such as Al adsorption in organic matter [35], which limits the possibility of generating secondary silicate minerals by precipitation, as both $\mathrm{Si}$ and $\mathrm{Al}$ are required in this process [36]. The acidic $\mathrm{pH}$ found in forests might facilitate Al dissolution, because low $\mathrm{pH}$ stimulates the desorption of Al complexes, releasing Al that leaches to the deeper layers [18]. Croplands, however, typically have lower soil organic matter stocks, and therefore less ability 

content $[37,38]$ and tends to retard dissolution processes, either by phytoliths or by secondary minerals.

247 Additionally, croplands studied here registered the highest reactivity values calculated using the model, when compared to the other sites, in both organic and mineral horizons (Figure 5). In forests and pastures the reactivity is higher in the deeper layers, which again corroborates the observation that this effect is closely linked to the presence of non-biogenic pools, however, croplands register the highest values even in the deeper layers. but never as high as in the croplands. As suggested by some authors [28], the biogenic silica depletion observed in these croplands might stimulate the weathering of clay minerals, probably through plant mechanisms of search for dissolved $\mathrm{Si}$, thus not only increasing non-biogenic pools but also increasing their intrinsic reactivity. In addition to active mineral dissolution by plants, chemical equilibrium also likely plays a role. If there is less $\mathrm{Si}$ in solution coming from the BSi dissolution, it will shift the chemical equilibrium toward more mineral dissolution. The presence of plant growth-promoting bacteria in the rhizosphere can be particularly significant in croplands, and act as a stimulator for the availability of nutrients [39, 40], and eventually also Si.

These results must be however, put in context for this specific land use gradient, which was established for a specific climate, parent material, weathering degree and topography, all of which are constant for all the sites. Other gradients, established for another set of conditions might result in different outcomes, especially concerning the abundance and type of non-biogenic Si pools present. These factors influence water availability in the pores and soil-water contact time [18]. Also parent material and weathering degree influence the pedogenic source of Si [41]. Also, land management is crucial for the assessment of the variables used in this study for croplands, which re-enforces the anthropogenic influence on the Si terrestrial cycle [42]. Agricultural management practices that potentiate the recycling of $\mathrm{Si}$ into the soil, such as residue maintenance and crop rotation [43] might balance the negative effect of Si export from the system through harvesting [44].

\section{Conclusions}

Land use impacts the Si cycle by altering the vegetation and consequently the accumulation of Si in plants and its recycling rate in the top soil $[23,24]$. These alterations also modify the distribution of biogenic and non-biogenic 
271 Si pools along the soil profile. In this work, we have additionally explored these pools dynamisc under batch

272 dissolution conditions, thus expanding the effects of land use change in the Si cycle.

273 The batch experiment presented here shows that BSi and non-BSi enriched samples have distinct Si and Al 274 dissolution curves in conditions that replicate the natural environment. While BSi-rich samples displayed an 275 approximately linear Si dissolution curve and low Al concentrations, the samples dominated by non-biogenic pools 276 show a non-linear increase of both Si and Al at variable concentrations, resulting from the fact that both elements 277 are coming from the same source. These differences resulted in lower $S_{\text {ini }}$ concentrations for BSi-rich samples when 278 compared to the non-biogenic ones. These findings highlight that, in the short-term, Si concentration in water is controlled by the secondary/pedogenic minerals and Si adsorbed to hydroxides pools rather than by phytoliths. concentrations, while the top soils, which are usually organic and filled with phytoliths, do not contribute significantly to the short-term availability of Si. In forest and pastures sites, where $\mathrm{O}$ and A horizons are significantly different from the mineral horizons, phytoliths are abundant down to $40 \mathrm{~cm}$ deep and the $\mathrm{Si}_{\text {ini }}$ concentrations are lower than in the deeper horizons, where pedogenic Si pools begin to interfere. On the other hand, croplands show higher $\mathrm{Si}_{\mathrm{ini}}$ concentrations at the top, because of phytolith depletion and the effects of agricultural activities causing horizons to mix.

\section{Acknowledgments} from Fundação para a Ciência e Tecnologia (FCT). 
293 1. Conley DJ, Carey JC (2015) Silica cycling over geologic time. Nat Publ Gr 8:431-432.

2942 2. Berner AR, Lasaga AC, Garrels RM (1983) The carbonate silicate geochemical cycle and its effect on atmosphere carbon dioxide 295 over the past 100 million years. Am J Sci 283:641-683 Beaulieu E, Goddéris Y, Donnadieu Y, et al (2012) High sensitivity of the continental-weathering carbon dioxide sink to future climate change. Nat Clim Chang 2:346-349.

Tréguer PJ, De La Rocha CL (2013) The world ocean silica cycle. Ann Rev Mar Sci 5:477-501. https://doi.org/10.1146/annurevmarine-121211-172346

300 5. Conley DJ (1997) Riverine contribution of biogenic silica to the oceanic silica budget. Limnol Oceanogr 42:774-777 Smis A, Damme S, Struyf E, et al (2010) A trade-off between dissolved and amorphous silica transport during peak flow events (Scheldt river basin, Belgium): impacts of precipitation intensity on terrestrial Si dynamics in strongly cultivated catchments. Biogeochemistry 106:475-487.

304 7. Conley DJ (2002) Terrestrial ecosystems and the global biogeochemical silica cycle. Global Biogeochem Cycles 16:1121.

305 8. Carey JC, Fulweiler RW (2012) The terrestrial silica pump. PLoS One 7:e52932. https://doi.org/10.1371/journal.pone.0052932

306 9. Struyf E, Conley DJ (2012) Emerging understanding of the ecosystem silica filter. Biogeochemistry 107:9-18.

10. Alexandre A, Meunier J-D, Colin F, Koud J-M (1997) Plant impact on the biogeochemical cycle of silicon and related weathering processes. Geochim Cosmochim Acta 61:677-682

309 11. Piperno D (2006) Phytoliths: A Comprehensive Guide for Archaeologists and Paleoecologists. Oxford

310 12. Guntzer F, Keller C, Meunier J-D (2011) Benefits of plant silicon for crops: a review. Agron Sustain Dev 32:201-213.

311 13. Bartoli F, Wilding LP (1980) Dissolution of Biogenic Opal as a Function of its Physical and Chemical Properties. Soil Sci Soc Am J 44:873-878

14. Fraysse F, Pokrovsky OS, Meunier J-D (2010) Experimental study of terrestrial plant litter interaction with aqueous solutions.

15. Cornelis J-T, Weis D, Lavkulich L, et al (2014) Silicon isotopes record dissolution and re-precipitation of pedogenic clay minerals in a podzolic soil chronosequence. Geoderma 235-236:19-29.

16. Cornelis JT, Dumon M, Tolossa AR, et al (2014) The effect of pedological conditions on the sources and sinks of silicon in the Vertic Planosols in south-western Ethiopia. Catena 112:131-138.

18. Ronchi B, Clymans W, Barão ALP, et al (2013) Transport of Dissolved Si from Soil to River: A Conceptual Mechanistic Model. Silicon 5:115-133.

19. Georgiadis A, Sauer D, Herrmann L, et al (2014) Testing a new method for sequential silicon extraction on soils of a temperatehumid climate. Soil Res 52:645.

20. Barão L, Vandevenne F, Clymans W, et al (2015) Alkaline-extractable silicon from land to ocean: A challenge for biogenic silicon determination. Limnol Oceanogr Methods 13:. https://doi.org/10.1002/lom3.10028

21. Blecker SW, McCulley RL, Chadwick O a., Kelly EF (2006) Biologic cycling of silica across a grassland bioclimosequence. Global Biogeochem Cycles 20:1-11.

22. Cornelis JT, Titeux H, Ranger J, Delvaux B (2011) Identification and distribution of the readily soluble silicon pool in a temperate forest soil below three distinct tree species. Plant Soil 342:369-378.

23. Struyf E, Smis A, Van Damme S, et al (2010) Historical land use change has lowered terrestrial silica mobilization. Nat Commun 1:129.

24. Vandevenne F, Struyf E, Clymans W, Meire P (2012) Agricultural silica harvest: have humans created a new loop in the global silica cycle? Front Ecol Environ 10:243-248. 
26. Unzué-Belmonte D, Ameijeiras-Mariño Y, Opfergelt S, et al (2017) Land use change affects biogenic silica pool distribution in a subtropical soil toposequence. Solid Earth 8:737-750.

27. Keller C, Guntzer F, Barboni D, Meunier J (2012) Impact of agriculture on the Si biogeochemical cycle : Input from phytolith studies. Comptes Rendus Geosci 344:739-746

28. Vandevenne FI, Barão L, Ronchi B, et al (2015) Silicon pools in human impacted soils of temperate zones. Global Biogeochem Cycles 29:. Oceanogr 48:1-23.

31. Clymans W, Barão L, Van Der Putten N, et al (2015) The contribution of tephra constituents during biogenic silica determination:

32. Saccone L, Conley DJ, Koning E, et al (2007) Assessing the extraction and quantification of amorphous silica in soils of forest and Implications for soil and palaeoecological studies. Biogeosciences 12:.

34. Clymans W, Struyf E, Govers G, et al (2011) Anthropogenic impact on amorphous silica pools in temperate soils. Biogeosciences 8:2281-2293.

35. Berggren D, Mulder J (1995) The role of organic matter in controlling aluminum solubility in acidic mineral soil horizons. Geochim Cosmochim Acta 59:4167-4180. Rothamsted. Plant Soil 352:173-184. 619. 


\section{Table Captions}

Table 1 - Soil samples characterization: content of biogenic silicon (BSi), non-BSi1, non-BSi2 and non-BSiz; soil pH ; cation exchange capacity (CEC) in $\mathrm{mg} \mathrm{g}^{-1}$; organic carbon in $\mathrm{mg} \mathrm{g}^{-1}$; soil water content in \% ; and sand and clay content in \%.

\section{Figure Captions}

Figure 1-Representation of the Si dissolution curve and the parameters considered in the non-linear model used: Sini is the Si concentration in time 0 after the mixture of soil and water; Sidis is the concentration achieved in the batch experiment, and $k_{s i}$ is the sample reactivity.

Figure 2 - Dissolution curves in the batch experiment of Meerdaal (left) and Ronquières (right) Forests (in $\mu \mathrm{mol} \mathrm{I}^{-}$ ${ }^{1}$ ) for Silicon (upper) and Aluminium (lower).

Figure 3 - Dissolution curves in the batch experiment of Blégny (left) and Herve (right) Pastures (in $\mu \mathrm{mol}^{-1}$ ) for Silicon (upper) and Aluminium (lower).

Figure 4 - Dissolution curves in the batch experiment of Ganspoel (left) and Velm (right) Croplands (in $\mu \mathrm{mol}^{-1}$ ) for Silicon (upper) and Aluminium (lower).

Figure 5 - Distribution of Sini, Sidis and ksifor Forests (white), Pastures (grey) and Croplands (black)

Figure 6 - Correlation between Si ini $\left(\mathrm{mg} \mathrm{g}^{-1}\right)$ at $\mathrm{pH} \mathrm{4,} 7$ and 10 and SicaCl2 from Vandevenne et al. (2015). The Spearman's correlation coefficient " $\rho$ " is indicated for each $\mathrm{pH}$ treatment. 
Table 1

\begin{tabular}{|c|c|c|c|c|c|c|c|c|c|c|c|c|c|}
\hline $\begin{array}{c}\text { Depth } \\
\text { (cm) }\end{array}$ & $\begin{array}{l}\text { Land } \\
\text { Use }\end{array}$ & Horizon & $\begin{array}{c}\text { AlkExSi } \\
\left(\mathbf{m g ~ g}^{-1}\right)\end{array}$ & $\begin{array}{c}\mathbf{B S i} \\
\left(\mathbf{m g} \mathbf{g}^{-1}\right)\end{array}$ & $\begin{array}{c}\text { non- } \\
\mathbf{B S i}_{1} \\
\left(\mathrm{mg} \mathrm{g}^{-1}\right)\end{array}$ & $\begin{array}{c}\text { non- } \\
\mathbf{B S i}_{2} \\
\left(\mathrm{mg} \mathrm{g}^{-1}\right)\end{array}$ & $\begin{array}{c}\text { non- } \\
\mathbf{B S i}_{3} \\
\left(\mathbf{m g ~ g}^{-1}\right)\end{array}$ & $\begin{array}{l}\text { Soil } \\
\text { pH }\end{array}$ & $\begin{array}{c}\text { CEC } \\
(\mathbf{m e q} \\
\left.100 \mathrm{~g}^{-1}\right)\end{array}$ & $\begin{array}{l}\text { Organic } \\
\text { carbon } \\
\left(\mathrm{mg} \mathrm{g}^{-1}\right)\end{array}$ & $\begin{array}{c}\text { Soil } \\
\text { water } \\
(\%)\end{array}$ & $\begin{array}{c}\text { Sand } \\
(\%)\end{array}$ & $\begin{array}{l}\text { Clay } \\
(\%)\end{array}$ \\
\hline 2 & \multirow{5}{*}{ 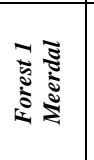 } & $\mathrm{Oi}$ & 3.77 & 3.77 & 0 & 0 & 0.0002 & 3.91 & 28.96 & 97.14 & 27 & 56.79 & 2.21 \\
\hline 22 & & A & 3.79 & 2.60 & 0 & 0 & 1.20 & 4.33 & 4.55 & 17.68 & 9 & 35.66 & 3.96 \\
\hline 42 & & $\mathrm{E}$ & 2.46 & 0 & 0 & 1.72 & 0.74 & 4.86 & 2.21 & 5.36 & 9 & 33.64 & 5.44 \\
\hline 82 & & $\mathrm{Bw}$ & 3.50 & 0 & 0 & 1.04 & 2.46 & 5.26 & 4.31 & - & 16 & 29.00 & 7.06 \\
\hline 147 & & $\mathrm{C}$ & 3.46 & 0 & 0 & 3.46 & 0 & 5.04 & 3.85 & - & 18 & 77.56 & 3.03 \\
\hline $6^{*}$ & \multirow{5}{*}{ 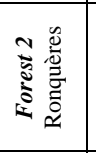 } & Oe & 5.08 & 5.08 & 0 & 0 & 0 & - & 19.67 & 99.70 & 29 & 67.51 & 1.48 \\
\hline 24 & & $\mathrm{AB}$ & 3.68 & 2.18 & 0 & 0 & 1.50 & - & 5.15 & - & 13 & 32.29 & 3.73 \\
\hline 49 & & B1 & 4.09 & 0 & 0 & 2.54 & 1.55 & 6.49 & 7.33 & 2.95 & 19 & 59.37 & 2.99 \\
\hline 67 & & $\mathrm{Bg}$ & 4.86 & 0 & 0 & 4.86 & 0 & 5.59 & 10.91 & 2.40 & 21 & 25.41 & 6.85 \\
\hline 145 & & $\mathrm{Bg}$ & 2.00 & 0 & 2.00 & 0 & 0 & 6.97 & 10.52 & - & 21 & 20.97 & 6.82 \\
\hline 2 & \multirow{10}{*}{ 总 } & $\mathrm{A}$ & 8.53 & 8.52 & 0 & 0 & 0.01 & 5.96 & 14.40 & 60.47 & 42 & 38.12 & 2.83 \\
\hline 6 & & A & 6.81 & 6.12 & 0 & 0.69 & 0 & 5.71 & 14.40 & 60.47 & 37 & 33.31 & 3.28 \\
\hline $8^{*}$ & & A & 7.77 & 7.34 & 0 & 0 & 0.01 & 5.59 & 14.40 & 39.82 & 34 & 31.52 & 3.40 \\
\hline 12 & & A & 8.30 & 0.00 & 0 & 8.24 & 0.06 & 5.90 & 9.43 & 31.94 & 26 & 30.12 & 3.63 \\
\hline $28^{*}$ & & B & 3.03 & 2.96 & 0 & 0 & 0.07 & 6.53 & 6.28 & 7.69 & 25 & 19.70 & 4.93 \\
\hline 52 & & B & 2.91 & 1.44 & 0 & 0 & 1.47 & 7.07 & 4.93 & 2.63 & 25 & 23.41 & 5.34 \\
\hline $72^{*}$ & & $\mathrm{Bg}$ & 4.11 & 0 & 0 & 3.34 & 0.78 & 6.96 & 11.52 & - & 38 & 24.17 & 4.68 \\
\hline 102 & & $\mathrm{Bg}$ & 4.08 & 0 & 3.57 & 0 & 0.51 & 6.64 & 29.81 & - & 45 & 22.92 & 4.90 \\
\hline 124 & & $\mathrm{Bg}$ & 58.40 & 0 & 58.40 & 0 & 0 & 7.96 & 29.03 & - & 36 & 16.03 & 8.40 \\
\hline 144 & & $\mathrm{Bg}$ & 54.64 & 0 & 54.64 & 0 & 0 & 7.94 & 32.63 & - & 32 & 15.76 & 8.70 \\
\hline 6 & \multirow{4}{*}{ 芯 $\sim$} & A2 & 3.85 & 3.84 & 0 & 0 & 0.004 & 6.88 & 11.99 & 61.39 & 31 & 28.53 & 4.37 \\
\hline 22 & & A2 & 2.45 & 2.29 & 0 & 0 & 0.16 & 6.94 & - & 37.09 & 8 & 24.63 & 4.86 \\
\hline 53 & & $\mathrm{E}$ & 18.01 & 0 & 0 & 14.93 & 3.08 & 7.00 & 6.42 & 5.42 & 14 & 13.97 & 9.77 \\
\hline 182 & & $\mathrm{~B}$ & 76.16 & 0 & 76.16 & 0 & 0 & 7.07 & 29.15 & - & 35 & 28.42 & 6.44 \\
\hline 2 & \multirow{7}{*}{ 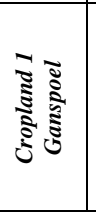 } & $\mathrm{Ap}$ & 3.61 & 2.10 & 0 & 0 & 1.51 & 7.18 & 13.69 & 17.46 & 13 & 31.84 & 5.48 \\
\hline $12^{*}$ & & Ap & 3.78 & 2.25 & 0 & 0.18 & 1.36 & 6.69 & 10.05 & 13.97 & 15 & 18.39 & 6.36 \\
\hline $22 *$ & & Ap & 4.19 & 2.93 & 0 & 0 & 1.26 & 7.41 & 8.82 & 10.94 & 17 & 26.31 & 5.78 \\
\hline 32 & & Ap & 3.29 & 0 & 0 & 3.29 & 0 & 7.51 & 8.11 & 8.89 & 17 & 26.16 & 6.07 \\
\hline $47^{*}$ & & $\mathrm{Bw}$ & 4.35 & 0 & 0 & 4.35 & 0 & 7.61 & 8.53 & 4.12 & 17 & 20.59 & 6.49 \\
\hline 77 & & $\mathrm{Bw}$ & 5.82 & 0 & 0 & 5.82 & 0 & 7.21 & 10.16 & 3.63 & 18 & 19.39 & 7.64 \\
\hline 147 & & $\mathrm{~B}$ & 8.86 & 0 & 0 & 8.86 & 0 & 8.41 & 11.71 & - & 18 & 19.55 & 7.58 \\
\hline 2 & \multirow{6}{*}{ 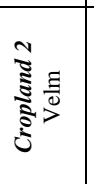 } & $\mathrm{Ap}$ & 7.18 & 0.42 & 0 & 6.76 & 0 & 7.58 & 16.82 & 19.58 & 13 & 19.67 & 6.24 \\
\hline $22^{*}$ & & Ap & 3.76 & 0.22 & 0 & 3.54 & 0 & 7.93 & 14.82 & 14.26 & 16 & 18.24 & 6.64 \\
\hline 52 & & Ap & 5.33 & 1.05 & 0 & 3.27 & 1.01 & 8.11 & 12.31 & 5.58 & 16 & 18.65 & 7.57 \\
\hline 82 & & $\mathrm{Bw}$ & 2.65 & 0 & 0 & 1.39 & 1.26 & 8.19 & 7.10 & - & 15 & 44.28 & 2.30 \\
\hline $132 * \#$ & & Bw & 4.12 & 0 & 0 & 3.60 & 0.52 & 7.80 & 12.82 & - & 17 & 19.86 & 7.61 \\
\hline 192 & & $\mathrm{BC}$ & 7.01 & 0 & 0 & 7.01 & 0 & - & 12.84 & - & 18 & 16.26 & 9.22 \\
\hline
\end{tabular}

*samples not used in batch experiments at $\mathrm{pH} 4$

\#samples not used in batch experiments at $\mathrm{pH} 7$ 
Fig 1

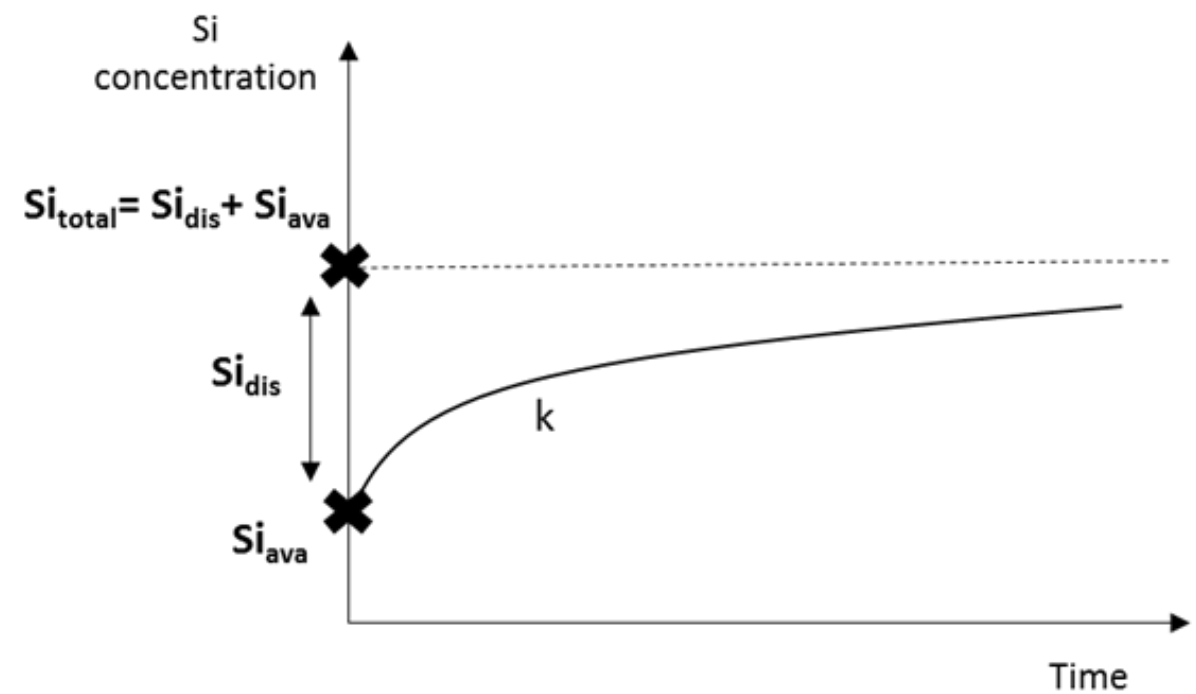


Fig 2

Meerdaal
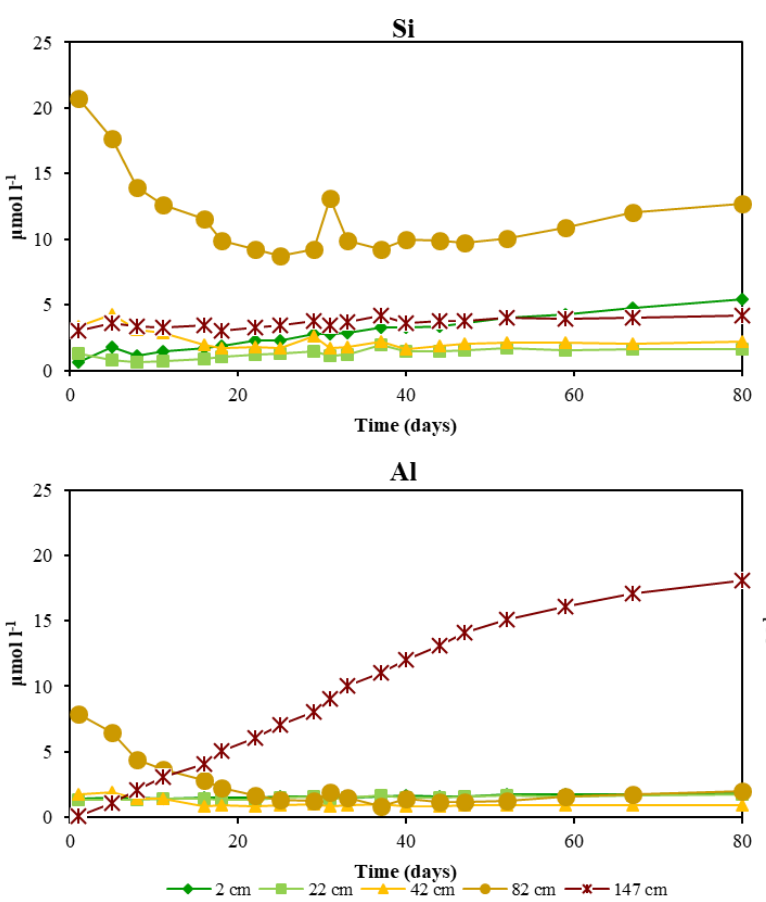

Ronquières
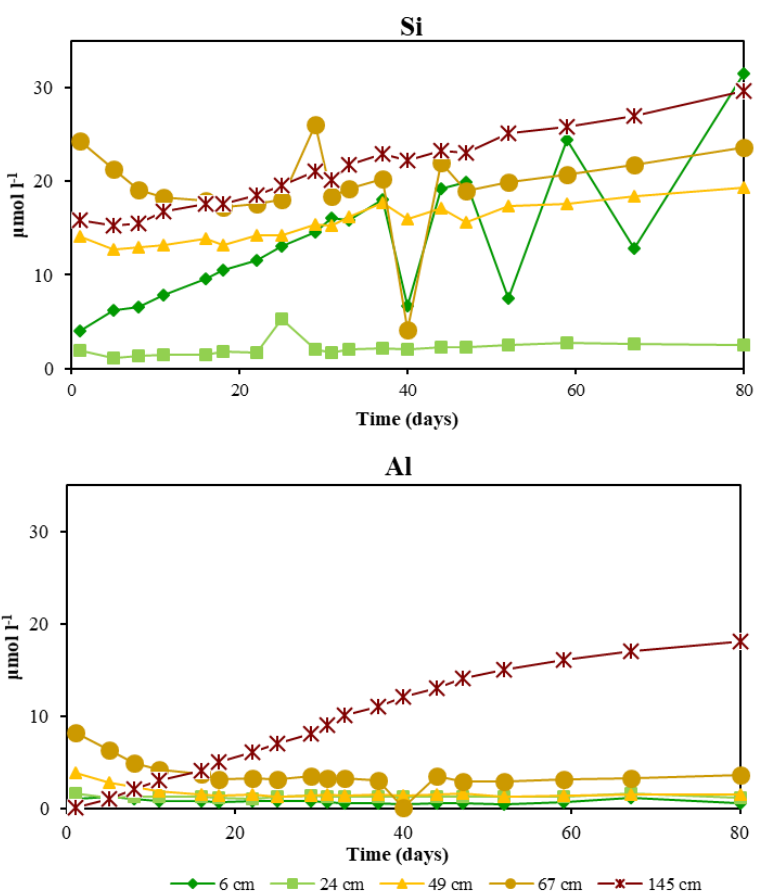
Fig 3

Blegny

Si

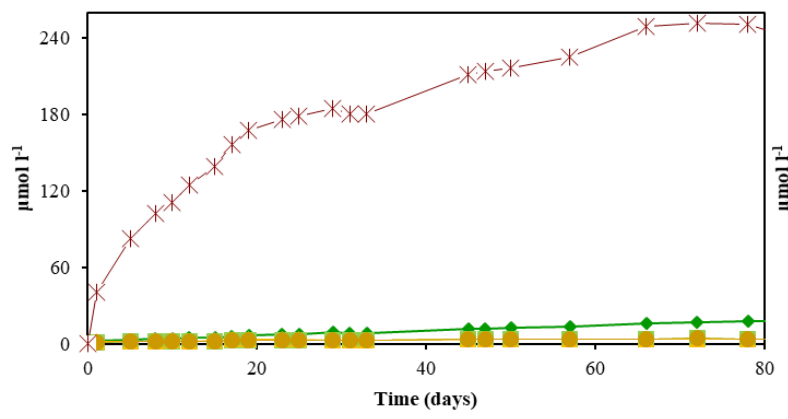

Al

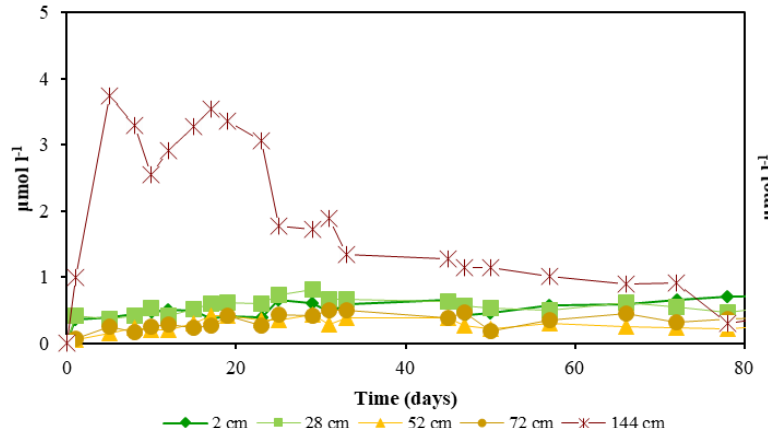

Herve

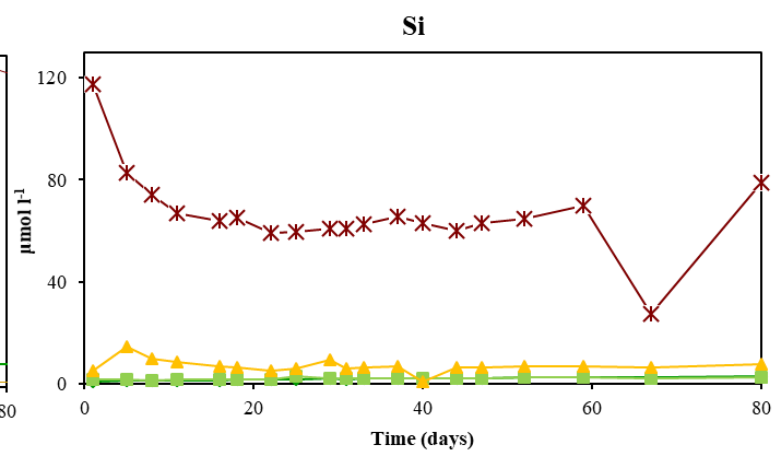

Al

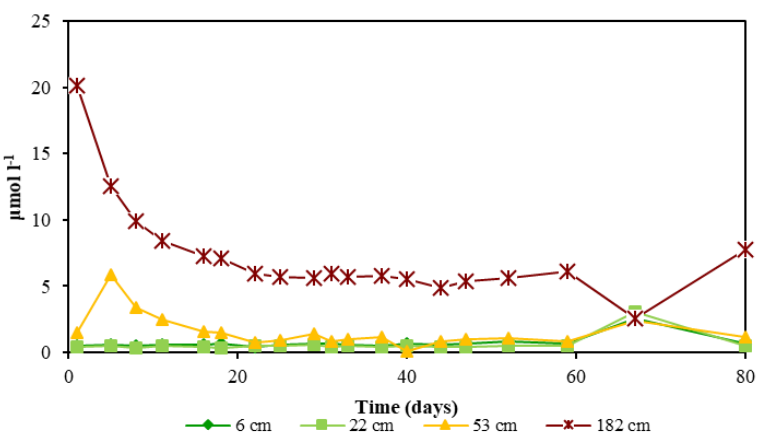


Fig 4

Ganspoel

Si

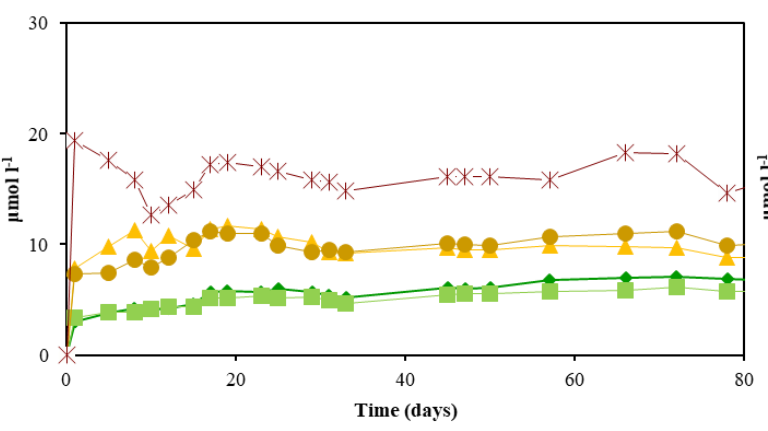

Al

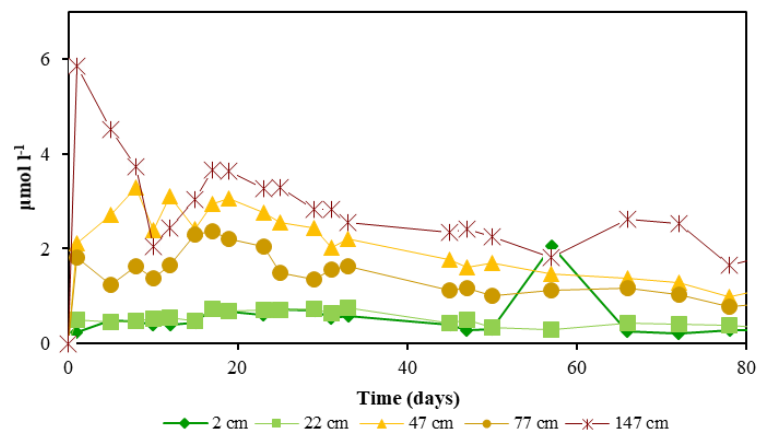

Velm

Si

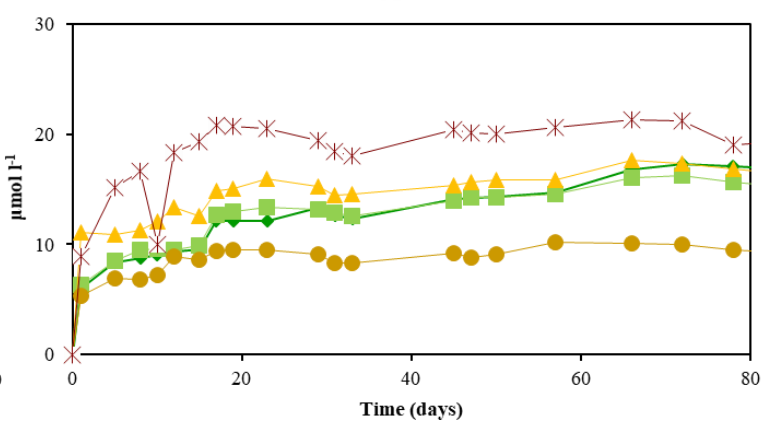

Al

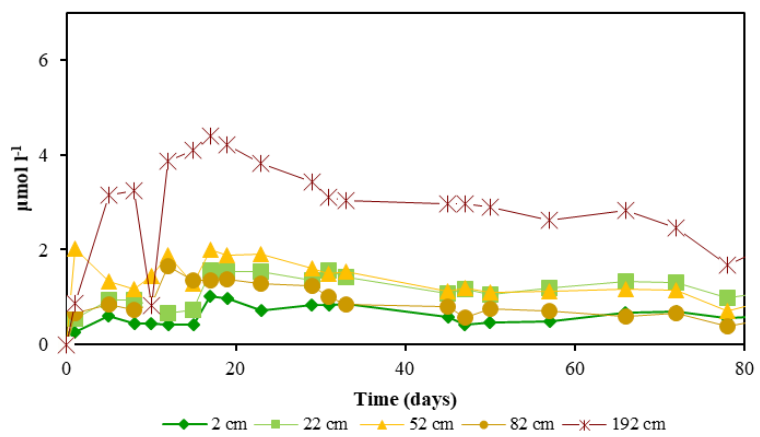


Fig 5
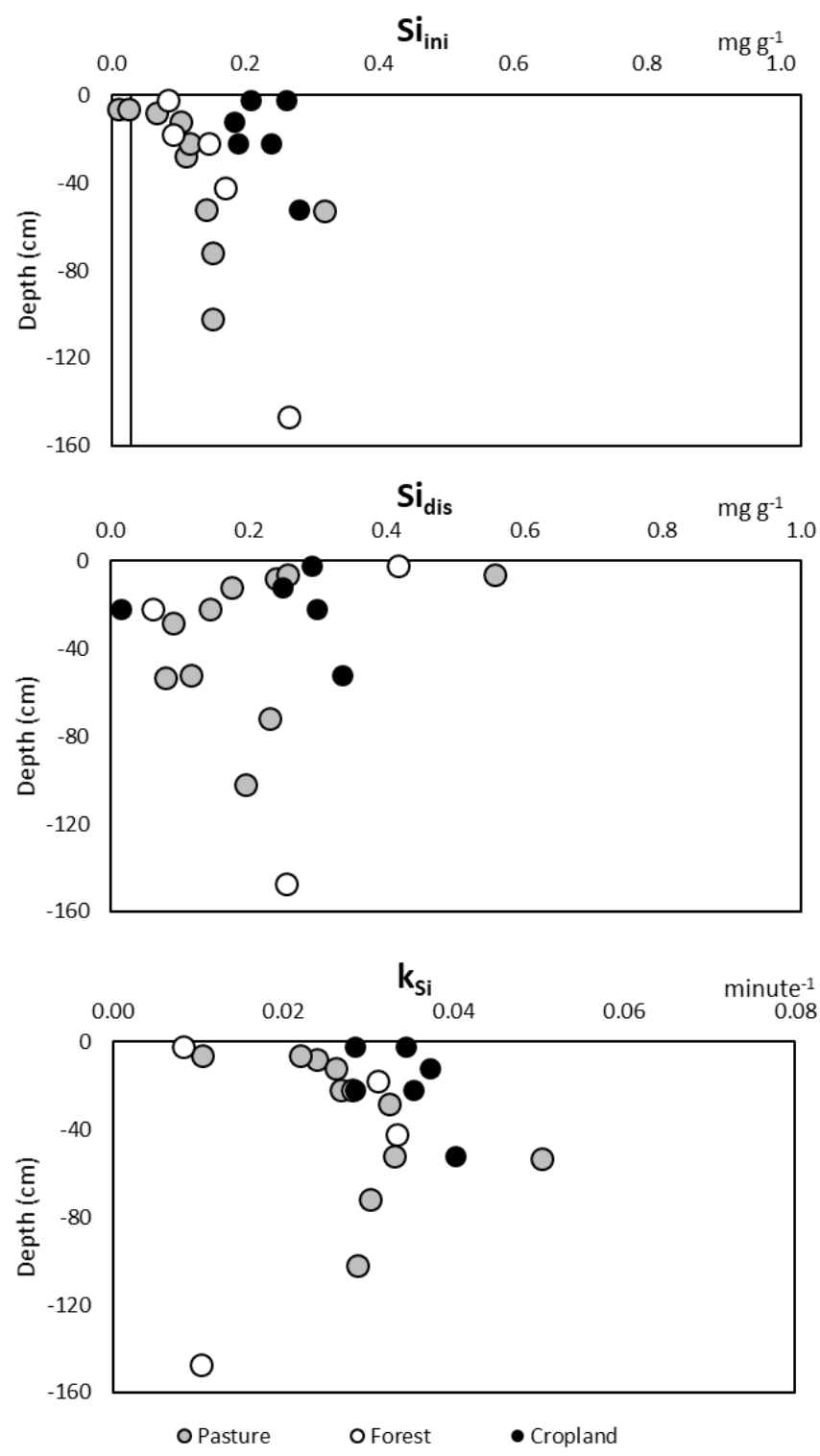
Fig 6
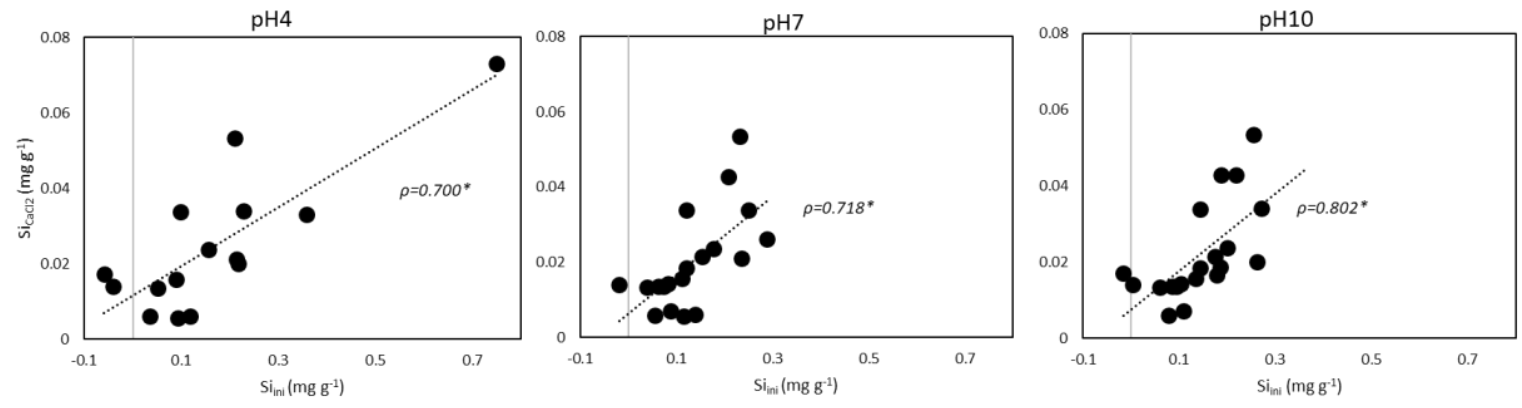

* Correlation is significant at the 0.01 level 